\title{
Amyloidosis cutis dyschromia
}

INSERM

\section{Source}

INSERM. (1999). Orphanet: an online rare disease and orphan drug data base.

Amyloidosis cutis dyschromia. ORPHA:319635

Amyloidosis cutis dyschromia is a rare primary cutaneous amyloidosis characterized by macular or reticulate hyperpigmentation with symmetrically distributed guttate hypo- and hyperpig mented lesions which progress gradually over the years to involve almost the entire body (with relative sparing of the face, hands, feet and neck). Patients are usually asymptomatic, however mild pruritus may be associated. Amyloid deposition in the papillary dermis is observed on skin biopsy. Systemic amyloidosis is not present and association with generalized morphea, atypical Parkinsonism, spasticity, motor weakness or colon carcinoma is rare. 